\title{
AWARENESS AND USE OF DIRECTORY OF OPEN ACCESS JOURNALS (DOAJ) AMONG THE FACULTIES OF ARTS AND SCIENCE COLLEGES IN PUDUCHERRY - A STUDY
}

\author{
Raju@Munisamy \\ Research Scholar, Department of Library and Information Science \\ Annamalai University, Annamalai Nagar, Tamilnadu, India

\section{Dr. P. Sivaraman} \\ Associate Professor, Department of Library and Information Science, \\ Annamalai Nagar, Tamil Nadu, India \\ Email: psraman.p@gmail.com
}

\begin{abstract}
The study explores the awareness and use of the journals covered in Directory of Open Access Journals for teaching-learning among the faculties working in arts and science colleges in Puducherry. A survey was conducted in ten such colleges to obtain the opinion of 143 faculties towards this direction through a structured questionnaire. The study revealed that that majority of the respondents were aware of DOAJ database and $50 \%$ to $85 \%$ of the faculties made use of the journals indexed in DOAJ database for various primary purposes like Preparing for seminars/ conferences, etc. (56.08\%), Teaching (52.2\%), conducting Research (49.49\%), and Self-Learning (48.38\%). Writing Journal Articles (44.07\%), and Lecture Notes (38.52\%) were found to be unexpectedly the secondary purposes. Frequency and time spent by the respondents towards the use of DOAJ database were found to be significant. It is quite encouraging that majority of the respondents were satisfied with the usage of DOAJ in terms of coverage and convenience. However, there are certain problems also identified, based on the opinion of the respondents, such as No Feedback Mechanism' and 'Slow Speed'.
\end{abstract}

Key words: open access journals, DOAJ, open educational resources, Puducherry, Arts and Science Colleges, teaching-learning resources.

Cite this Article: Raju@Munisamy and Dr. P. Sivaraman, Awareness and Use of Directory of Open Access Journals (DOAJ) among the Faculties of Arts and Science Colleges in Puducherry - A Study. International Journal of Library \& Information Science, 7(1), 2018, pp. 94-101.

http://iaeme.com/Home/issue/IJLIS?Volume=7\&Issue=1 


\section{INTRODUCTION}

Before the existence of open access movement in the earliest twenty first century, there was a digital divide of information between have's and have not's. To bridge the divide the open access movement came into existence. The information rich always had the privileges of accessing to plenty of resources conveniently while the other counterpart had a lot of restrictions in accessibility to basic information. To eliminate this barrier, many initiatives were taken in India and other countries to make scholarly publications accessible to everyone for free. Directory of Open Access Journals (DOAJ) is one of such initiatives which paved the way to scholarly community for having access to quality scholarly journals irrespective of the discipline at free of cost. "The DOAJ was launched in 2003 at Lund University, Sweden 300 open access journals. Currently, the database contains 12000 open access journals covering all areas of science, technology, medicine, social science, and humanities" (doaj.org/about). In view of the above, the authors intended to assess the extent of utilization of the Journals covered in DOAJ by the faculties working in arts and science colleges located in Puducherry.

\section{LITERATURE REVIEW}

There are three different routes, green-gold-diamond to have access to electronic resources. It was noticed that majority of the respondents were aware of the green and gold routes while they were not well acquainted with the diamond route (Bosah, 2017). A large majority of the respondents made use of online resources effectively, and particularly, out of various online sources e-journals were found to be the prominent source utilized daily by the respondents from both the institutions under study. Surprisingly it was found that the use of free educational resources available online were very popular among the respondents (Ahmed, 2017; Mahadevamurthy \& Adithyakumari, 2015). With regard to the use of social media tools for academic purposes, it was observed that Instagram was used by majority of the participants on daily basis spending most of their time followed by Snapchat, Facebook, and Twitter (Alhabash et al (2017). It is a common phenomenon that majority of the users are not well-versed with the search and retrieval of précised information from online resources. Towards this direction, Malone and Videon (2015) proved that the provision of instructions on how to make use of electronic resources can significantly enhance the use of these online resources optimally.

Availability of open access journals is a boon to the academia. Though there are open access journals available in plenty covering all the subjects, the usage of such journals are not up to the expectations. On the one hand, a few studies reported that the researchers were still in favour open access journals and the same was popular, and utilized by the respondents fairly (Bartle \& Walton, 1996; Eqbal \& Khan, 2007). On the other hand, it was observed from a few studies that the open access journals are not popular among the researchers and the utilization of these journals was found to be low due to lack of awareness. The studies suggested that the libraries should take initiatives to create awareness among the stakeholders to enhance the use of open access journals which are supplement to subscribed journals (Ojedokun \& Owolabi, 2003; Badu \& Markwei, 2005; Mallik, Saxena \& Roy, 2007). However, a few problems in the use of open access journals such as inadequate end-user training, poor connectivity, and limited access to PCs, poor search skills, and low bandwidth were reported in the earlier studies (Manda, 2005; Smith, 2007). 


\section{OBJECTIVES OF THE STUDY}

The study was carried out with the following objectives:

- To study the level of awareness and the extent of use of DOAJ among the faculties of arts and science colleges in Puducherry;

- To identify the purpose and frequency of using of DOAJ by the respondents;

- To examine whether the use of DOAJ enhances the teaching learning skills of the respondents;

- To assess the level of satisfaction of the respondents on the use of DOAJ; and

- To ascertain the problems associated with the use of DOAJ by the respondents.

\section{RESEARCH DESIGN}

The research is based on the faculties working in the arts and science colleges located in Puducherry. The survey was conducted using census method covering all the following ten colleges:

- Indira Gandhi College of Arts \& Science (IGCAS)

- Rajiv Gandhi College of Arts \& Science (RGCAS)

- Kasthurba College of Arts \& Science (KCAS)

- Perunthalaivar Kamarajar College of Arts \& Science (PKCAS)

- Tagore College of Arts \& Science (TCAS)

- Bharathidasan College of Arts \& Science for Women (BCASW)

- Kanchi Mamuniver Centre for Post Graduate Studies (KMCPGS)

- Sarada Gangadaran College of Arts \& Science (SGCAS)

- Idhaya College of Arts \& Science for Women (ICASW)

- Achariya Arts \& Science College (AASC)

The data were collected using structured questionnaire. Proportionate stratified sampling was adopted A total of 180 questionnaires were distributed. Of which, 143 questionnaires duly filled in were received back with a response rate of 79.44 percent (Table 1). The abbreviations provided along side of the colleges will be used throughout the paper.

Table 1 Status of the questionnaires distributed vs. received

\begin{tabular}{|l|c|c|c|c|}
\hline \multicolumn{1}{|c|}{ Institution } & & Distributed & Received & $\begin{array}{c}\text { Response } \\
\text { Rate }\end{array}$ \\
\hline Achariya Arts \& Science College & AASC & 20 & 16 & 80.00 \\
\hline $\begin{array}{l}\text { Bharathidasan College of Arts \& Science for } \\
\text { Women }\end{array}$ & BCASW & 20 & 17 & 85.00 \\
\hline Idhaya College of Arts \& Science for Women & ICASW & 15 & 12 & 80.00 \\
\hline Indira Gandhi College of Arts \& Science & IGCAS & 15 & 11 & 73.33 \\
\hline $\begin{array}{l}\text { Kanchi Mamuniver Centre for Post Graduate } \\
\text { Studies }\end{array}$ & KMCPGS & 20 & 16 & 80.00 \\
\hline Kasthurba College of Arts \& Science & KCAS & 15 & 12 & 80.00 \\
\hline Perunthalaivar Kamarajar College of Arts \& Science & PKCAS & 20 & 15 & 75.00 \\
\hline Rajiv Gandhi College of Arts \& Science & RGCAS & 15 & 11 & 73.33 \\
\hline Sarada Gangadaran College of Arts \& Science & SGCAS & 20 & 17 & 85.00 \\
\hline Tagore College of Arts \& Science & TCAS & 20 & 16 & 80.00 \\
\hline Total & & 180 & 143 & 79.44 \\
\hline
\end{tabular}


Awareness and Use of Directory of Open Access Journals (DOAJ) among the Faculties of Arts and Science Colleges in Puducherry - A Study

\section{RESULTS AND DISCUSSION}

\subsection{Awareness on DOAJ}

Table 2 reveals the awareness level of the respondents on the journals covered in Directory of Open Access for Arts \& Science disciplines. The institution wise result indicates that out of 143 total faculties working in Arts \& Science colleges in Puducherry region, 134 faculties from BCASW were well aware of DOAJ that ranks first in order recording 93.71 percentage of awareness followed by AASC (89.51\%), KMCPGS (86.71\%), KCAS (83.22\%), IGCAS $(82.52 \%)$, SGCAS $(81.12 \%)$, TCAS $(79.72 \%)$, PKCAS $(79.02 \%)$, RGCAS $(78.32 \%)$, and ICASW (68.53\%).

Table 2 Institution wise awareness level of the faculties on DOAJ

\begin{tabular}{|c|c|c|}
\hline Institution & Awareness (N=143) & \% \\
\hline AASC & 128 & 89.51 \\
\hline BCASW & 134 & 93.71 \\
\hline ICASW & 98 & 68.53 \\
\hline IGCAS & 118 & 82.52 \\
\hline KMCPGS & 124 & 86.71 \\
\hline KCAS & 119 & 83.22 \\
\hline PKCAS & 113 & 79.02 \\
\hline RGCAS & 112 & 78.32 \\
\hline SGCAS & 116 & 81.12 \\
\hline TCAS & 114 & 79.72 \\
\hline
\end{tabular}

\subsection{Awareness on versus Use of DOAJ}

Based on the result of awareness on DOAJ, an attempt was made to analyse the use of DOAJ against awareness among the faculties. It was found that out of 114 faculties from TCAS, who were aware of DOAJ, 95 of them made use of DOAJ reporting 83.33 percent followed by PKCAS (83.19\%), KMCPGS (79.84\%), SGCAS (79.31\%), IGCAS (78.81\%), AASC (73.44\%), KCAS (72.27\%), BCASW (71.64\%), RGCAS (70.54\%), and ICASW (58.16\%).

Table 3 Awareness Vs. Use of DOAJ

\begin{tabular}{|c|c|c|c|c|}
\hline Institution & Awareness & $\mathbf{\%}$ & Use & $\mathbf{\%}$ \\
\hline AASC & 128 & 89.51 & 94 & 73.44 \\
\hline BCASW & 134 & 93.71 & 96 & 71.64 \\
\hline ICASW & 98 & 68.53 & 57 & 58.16 \\
\hline IGCAS & 118 & 82.52 & 93 & 78.81 \\
\hline KMCPGS & 124 & 86.71 & 99 & 79.84 \\
\hline KCAS & 119 & 83.22 & 86 & 72.27 \\
\hline PKCAS & 113 & 79.02 & 94 & 83.19 \\
\hline RGCAS & 112 & 78.32 & 79 & 70.54 \\
\hline SGCAS & 116 & 81.12 & 92 & 79.31 \\
\hline TCAS & 114 & 79.72 & 95 & 83.33 \\
\hline
\end{tabular}

\subsection{Purpose of Using DOAJ}

Table 4 presents the result on the purpose of using DOAJ by the faculties. The options given in the questionnaire were multiple in nature. The institution wise analysis revealed that out of total number of respondents from AASC, 58.82 percent of them made use of DOAJ for teaching purpose followed by the other purposes such as Self-Learning (43.44\%), conducting Research (43.28\%), Preparing for seminars/ conferences, etc. (61.72\%), Writing Journal 
Articles (42.23\%), and Lecture Notes (39.23\%). With regard to BCASW, 47.24 percent of the faculties made use of DOAJ for teaching purpose followed by the other purposes such as SelfLearning (52.34\%), conducting Research (53.67\%), Preparing for seminars/ conferences, etc. (69.32\%), Writing Journal Articles (52.12\%), and Lecture Notes (33.28\%). Similarly, the same observation was found in other institutions also. However, the overall result indicates that Preparing for seminars/ conferences, etc. was found to be the primary purpose sharing 56.08 percent followed by Teaching (52.2\%), conducting Research $(49.49 \%)$, Self-Learning (48.38\%), Writing Journal Articles (44.07\%), and Lecture Notes (38.52\%).

Table 4 Purpose of using DOAJ by the Faculties

\begin{tabular}{|c|c|c|c|c|c|c|}
\hline Institution & Teaching & $\begin{array}{c}\text { Self- } \\
\text { Learning }\end{array}$ & $\begin{array}{c}\text { conducting } \\
\text { Research }\end{array}$ & $\begin{array}{c}\text { Preparing for } \\
\text { seminars/ } \\
\text { conferences, etc. }\end{array}$ & $\begin{array}{c}\text { Writing } \\
\text { Journal } \\
\text { Articles }\end{array}$ & $\begin{array}{c}\text { Lecture } \\
\text { Notes }\end{array}$ \\
\hline AASC & 58.82 & 43.44 & 43.28 & 61.72 & 42,23 & 39.23 \\
\hline BCASW & 47.24 & 52.34 & 53.67 & 69.32 & 52.12 & 33.28 \\
\hline ICASW & 39.09 & 47.87 & 42.98 & 51.11 & 43.67 & 29.43 \\
\hline IGCAS & 57.61 & 56.71 & 45.16 & 53.27 & 46.17 & 37.65 \\
\hline KMCPGS & 49.29 & 43.23 & 41.83 & 49.22 & 39.03 & 41.23 \\
\hline KCAS & 54.22 & 38.84 & 53.11 & 55.16 & 42.16 & 36.67 \\
\hline PKCAS & 55.46 & 51.11 & 55.29 & 47.25 & 39.14 & 43.28 \\
\hline RGCAS & 56.67 & 48.43 & 48.44 & 53.28 & 36.92 & 40.13 \\
\hline SGCAS & 55.06 & 44.12 & 54.28 & 55.36 & 49.13 & 39.21 \\
\hline TCAS & 48.49 & 57.72 & 56.82 & 65.11 & 50.11 & 45.11 \\
\hline
\end{tabular}

\subsection{Frequency of Using DOAJ}

Table 5 illustrates the result of how frequently the faculties made use of the journals covered in DOAJ. The result shows that out of total number of respondents from AASC, 34.91 percent of them made use of DOAJ 'Daily' followed by Weekly (17.85\%), Fortnightly $(29.66 \%)$, Monthly (11.01\%), and Occasionally (6.57\%). With regard to BCASW, 20.17 percent of the faculties made use of DOAJ 'Daily' followed by 'Weekly' (21.32\%), Fortnightly (36.34\%), Monthly (13.45\%), and Occasionally (8.72\%). Similarly, the same observation was found in other institutions also. However, the overall result indicates that 26.5 percent of the faculties used DOAJ 'Fortnightly' followed by 'Occasionally' (23.64\%), 'Monthly' (18.87\%), 'Weekly' (18.02\%), and 'Daily' (12.97\%).

Table 5 Distribution of the Frequency of using DOAJ

\begin{tabular}{|c|c|c|c|c|c|}
\hline Institution & Daily & Weekly & Fortnightly & Monthly & Occasionally \\
\hline AASC & 34.91 & 17.85 & 29.66 & 11.01 & 6.57 \\
\hline BCASW & 20.17 & 21.32 & 36.34 & 13.45 & 8.72 \\
\hline ICASW & 8.92 & 11.50 & 27.34 & 32.32 & 19.92 \\
\hline IGCAS & 24.23 & 13.67 & 27.11 & 18.04 & 16.95 \\
\hline KMCPGS & 20.97 & 18.34 & 25.95 & 15.66 & 19.08 \\
\hline KCAS & 8.14 & 12.01 & 22.11 & 28.90 & 28.84 \\
\hline PKCAS & 11.01 & 21.26 & 22.16 & 17.01 & 28.56 \\
\hline RGCAS & 13.92 & 26.38 & 34.23 & 9.32 & 16.15 \\
\hline SGCAS & 14.46 & 16.45 & 30.78 & 30.99 & 7.32 \\
\hline TCAS & 9.34 & 13.67 & 23.77 & 11.36 & 41.86 \\
\hline
\end{tabular}


Awareness and Use of Directory of Open Access Journals (DOAJ) among the Faculties of Arts and Science Colleges in Puducherry - A Study

\subsection{Time spent in using DOAJ}

Table 6 highlights the result of time spent on weekly basis by the faculties to make use of DOAJ. The result indicates that out of total number of respondents from AASC, 31.21 percent of them spent ' $0-2$ hrs/week' followed by '2-3 hrs/week' (16.99\%), '3-4 hrs/week' (31.2\%), ' $4-5$ hrs/week' (9.32\%), and '>5 hrs/week' (11.28\%). With regard to BCASW, 36.2 percent of the faculties spent ' $0-2 \mathrm{hrs} /$ week' followed by '2-3 hrs/week' (17.25\%), '3-4 hrs/week' (25.54\%), '4-5 hrs/week' (13.27\%), and ' $>5$ hrs/week' (7.74\%). Similarly, the same observation was found in other institutions also. However, the overall result indicates that 28.73 percent of them spent ' 0 -2 hrs/week' followed by '2-3 hrs/week' (23.26\%), '3-4 hrs/week' (24.32\%), '4-5 hrs/week' (14.48\%), and '>5 hrs/week' (9.22\%).

Table 6: Distribution of Time Spent per week in using DOAJ

\begin{tabular}{|c|c|c|c|c|c|}
\hline Institution & $\mathbf{0 - 2}$ hrs & $\mathbf{2 - 3}$ hrs & $\mathbf{3 - 4}$ hrs & $\mathbf{4 - 5}$ hrs & >5 hrs \\
\hline AASC & 31.21 & 16.99 & 31.20 & 9.32 & 11.28 \\
\hline BCASW & 36.20 & 17.25 & 25.54 & 13.27 & 7.74 \\
\hline ICASW & 37.78 & 33.39 & 12.50 & 11.34 & 4.99 \\
\hline IGCAS & 34.51 & 21.50 & 14.73 & 15.99 & 13.27 \\
\hline KMCPGS & 25.20 & 17.32 & 36.20 & 11.02 & 10.26 \\
\hline KCAS & 20.09 & 27.89 & 26.63 & 15.23 & 10.16 \\
\hline PKCAS & 17.71 & 34.65 & 26.06 & 13.28 & 8.30 \\
\hline RGCAS & 26.26 & 23.53 & 27.17 & 12.93 & 10.11 \\
\hline SGCAS & 15.24 & 19.21 & 27.44 & 30.18 & 7.93 \\
\hline TCAS & 43.05 & 20.89 & 15.75 & 12.20 & 8.11 \\
\hline
\end{tabular}

\subsection{Satisfaction level of the respondents with DOAJ}

Table 7 projects the result of satisfaction level of the faculties with the use of DOAJ. The result indicates that out of total number of respondents from AASC, 27.77 percent of them were 'Extremely Satisfied' with the use of DOAJ followed by 'Satisfied' (20.19\%), 'Moderate' (32.25\%), 'Dissatisfied' (12.02\%), and 'Extremely Dissatisfied' (7.77\%). With regard to BCASW, 32.29 percent of them were 'Extremely Satisfied' with the use of DOAJ followed by 'Satisfied' (20.61\%), 'Moderate' (32.2\%), 'Dissatisfied' (9.65\%), and 'Extremely Dissatisfied' (5.25\%). Similarly, the same observation was found in other institutions also. However, the overall result indicates that 22.57 percent of them were 'Extremely Satisfied' with the use of DOAJ followed by 'Satisfied' (27.39\%), 'Moderate' (29.37\%), 'Dissatisfied' (12.33\%), and 'Extremely Dissatisfied' (8.35\%).

Table 7 Distribution of Satisfaction Level of the faculties with the use of DOAJ

\begin{tabular}{|c|c|c|c|c|c|}
\hline Institution & $\begin{array}{c}\text { Extremely } \\
\text { Satisfied }\end{array}$ & Satisfied & Moderate & Dissatisfied & $\begin{array}{c}\text { Extremely } \\
\text { Dissatisfied }\end{array}$ \\
\hline AASC & 27.77 & 20.19 & 32.25 & 12.02 & 7.77 \\
\hline BCASW & 32.29 & 20.61 & 32.20 & 9.65 & 5.25 \\
\hline ICASW & 10.21 & 32.15 & 36.73 & 11.16 & 9.75 \\
\hline IGCAS & 33.61 & 28.02 & 18.84 & 11.00 & 8.53 \\
\hline KMCPGS & 25.71 & 20.02 & 34.61 & 12.11 & 7.55 \\
\hline KCAS & 21.48 & 29.18 & 24.33 & 16.15 & 8.86 \\
\hline PKCAS & 18.51 & 32.20 & 27.96 & 11.34 & 9.99 \\
\hline RGCAS & 23.00 & 22.39 & 35.55 & 9.05 & 10.01 \\
\hline SGCAS & 22.86 & 26.56 & 32.34 & 9.96 & 8.28 \\
\hline TCAS & 10.22 & 42.55 & 18.85 & 20.86 & 7.52 \\
\hline
\end{tabular}




\subsection{Problems faced by the respondents with DOAJ}

Besides the positive impact of using the journals covered in DOAJ database, the researchers intended to identify the constraints faced by the faculties of Arts \& Science while using DOAJ database based on the perception of the respondents. As shown in Table 8, 'No Feedback Mechanism' and 'Slow Speed' were found to be the major constraints in the usage of DOAJ database reporting the opinion of 62.24 percent of the respondents each. The other problems identified include Lack of up-to-date information (46.85\%), Lack of subject coverage (41.26\%), Lack of Quality (34.27\%), Inactive Links (32.87\%), Lack of user friendliness (30.07\%), Inadequate search facility (27.27\%), Lack of Time (27.27\%), Lack of Awareness (22.38\%), and Lack of Interest (16.08\%).

Table 8: Problems Faced by the respondents in using DOAJ

\begin{tabular}{|c|c|c|c|}
\hline S. No. & Problems Faced & No. of Responses (N=143) & \% \\
\hline 1 & Lack of Awareness & 32 & 22.38 \\
\hline 2 & Lack of Quality & 49 & 34.27 \\
\hline 3 & Inadequate search facility & 39 & 27.27 \\
\hline 4 & Lack of subject coverage & 59 & 41.26 \\
\hline 5 & Inactive Links & 47 & 32.87 \\
\hline 6 & Lack of user friendliness & 43 & 30.07 \\
\hline 7 & $\begin{array}{c}\text { Lack of up-to-date } \\
\text { information }\end{array}$ & 67 & 46.85 \\
\hline 8 & No Feedback Mechanism & 89 & 62.24 \\
\hline 9 & Slow Speed & 89 & 62.24 \\
\hline 10 & Lack of Time & 39 & 27.27 \\
\hline 11 & Lack of Interest & 23 & 16.08 \\
\hline
\end{tabular}

\section{FINDINGS AND CONCLUSION}

The study revealed that majority of the respondents were aware of DOAJ database and $50 \%$ to $85 \%$ of the faculties made use of the journals indexed in DOAJ database for various primary purposes like Preparing for seminars/ conferences, etc. $(56.08 \%)$, Teaching $(52.2 \%)$, conducting Research (49.49\%), and Self-Learning (48.38\%). Writing Journal Articles (44.07\%), and Lecture Notes (38.52\%) were found to be unexpectedly the secondary purposes. Frequency and time spent by the respondents towards the use of DOAJ database were found to be significant. It is quite encouraging that majority of the respondents were satisfied with the usage of DOAJ in terms of coverage and convenience. However, there are certain problems also identified, based on the opinion of the respondents, such as No Feedback Mechanism' and 'Slow Speed'. In view of the above findings, it could be concluded that the accessibility to DOAJ is a boon to the faculties working in Arts and Science colleges in Puducherry. It is suggested that user orientation or awareness programmes on DOAJ could be the possible mechanisms to eliminate some of the constraints by which the quality of teaching-learning and in the institutions under study can be enhanced.

\section{REFERENCES}

[1] Ahmed, S. M. Z. (2017). A survey of students' use of and satisfaction with university subscribed online resources in two specialized universities in a developing country, 5 .

[2] Alhabash, S., \& Ma, M. (2017). A Tale of Four Platforms: Motivations and Uses of Facebook, Twitter, Instagram, and Snapchat Among College Students?. Social Media+Society, 3(1), 2056305117469154. 
Awareness and Use of Directory of Open Access Journals (DOAJ) among the Faculties of Arts and Science Colleges in Puducherry - A Study

[3] Bosah, G., Okeji, C. C., \& Baro, E. E. (2017). Perceptions, preferences of scholarly publishing in Open Access journals: A survey of academic librarians in Africa. Digital Library Perspectives, 33(4), 378-394. https://doi.org/10.1108/DLP-03-2017-0011

[4] Badu, E., \&Markwei, E.(2005). Internet awareness and use in the University of Ghana. InformationDevelopment 21 (4): 260.268.

[5] Bartle, T., \& Walton, A. (1996). Awareness of electronic journals. Available: http://san.undo.org/gpgn/topics.php

[6] Directory of Open Access Journals (DOAJ). Available at doaj.org/about.

[7] Eqbal, M., \& Khan, A. (2007). Use of electronic journals by the research scholars of Faculty of Science and Faculty of Engineering, Amu, Aligarh: A comparative study. Library and Information Networking (NACLIN), DELNET, New Delhi, pp 98-132.

[8] Kumaresan, A \& Sivaraman, P (2010).Information search pattern of research scholars in Anna University: An Investigative study. Library Progress (International).30(2).199-214.

[9] Mahadevamurthy, $M$ and Adithyakumar, H. (2015). Electronic Information Resources In: Law Libraries: An Overview. Review of Research, 4(4), 1-10.

[10] Mallik, S., \& Roy, P. (2007). Online journals usage pattern: A case study of CDRI, Lucknow as a member of CSIR E-journals Consortium. Library and Information Networking (NACLIN), DELNET: 243-254.

[11] Manda, A. (2005). Electronic resources in Tanzania by academics. In: GL7 Conference Proceedings.TextRelease. Available: http://www.greynet.org/

[12] Malone, Debbie \& Videon, Carol (2015). Assessing undergraduate use of electronic resources: A quantitative analysis of works cited. Research Strategies, 15(3), 151-158.

[13] Muthu, M, Sivaraman, P (2013).Online public access catalogue (OPAC):An overview. International Journal of digital information \& knowledgement.1(2).79-89.

[14] Natarajan, K., Suresh, B., Sivaraman, P., \& Sevukan, R. (2010). Use and user perception of electronic resources in Annamalai University: a case study. Annals of Library and Information Studies, 57, 59-64.

[15] Ojedokun, A., \&Owolabi, A. (2003).Internet use for teaching and research in Botswana. Africa Journal of Library, Archive and information science 13(1):43-53.

[16] Smith, T. (2007). Survey of open access barriers to scientific information: providing an appropriate pattern for scientific communication in Iran. In: GL7 Conference Proceedings. TextRelease. Available: http://www.greynet.org/

[17] Sevukan, R. \& Sivaraman P. (2008).Use of Internet service in Pondicherry university Library: An evaluative study. Indian Journal of Information Science and services 2(1):511 .

[18] Sivaraman, P and Rajangam, C. (2017). Perception of faculty members on the library resources and services of selected arts and science government aided colleges affiliated to Bharathidasan University, Tiruchirappali - a survey. International Journal of library \& Information Science (IJLIS). 6 (6):37-44. 